\title{
Knowledge of Togolese Doctors on Biological Effects of Ultrasound and Their Attitudes towards the Ultrasonographic Explorations Performed in Lome (Togo)
}

\author{
Kokou Adambounou1,2, El Hadji Amadou Lamine Bathily3, Amegninou Mawuko Yao Adigo², \\ Pihou Gbandé2, Kpalma Duga Bakpatina-Batako', Lantam Sonhaye2, \\ Théophile Lincoln Tapsoba ${ }^{4}$, Komlanvi Adjenou ${ }^{2}$
}

\author{
${ }^{1}$ Laboratoire de Biophysique Médicale, Université de Lome, Lome, Togo \\ ${ }^{2}$ Service d'Imagerie Médicale, CHU Campus, Lome, Togo \\ ${ }^{3}$ Service de Médecine Nucléaire HOGGY, Dakar, Senegal \\ ${ }^{4}$ Service de Médecine Nucléaire CHU YO, Ouagadougou, Burkina-Faso \\ Email:kadambounou@yahoo.fr
}

How to cite this paper: Adambounou, K., Bathily, E.H.A.L., Adigo, A.M.Y., Gbandé, P., Bakpatina-Batako, K.D., Sonhaye, L., Tapsoba, T.L. and Adjenou, K. (2018) Knowledge of Togolese Doctors on Biological Effects of Ultrasound and Their Attitudes towards the Ultrasonographic Explorations Performed in Lome (Togo). Open Journal of Biophysics, 8, 1-8.

https://doi.org/10.4236/ojbiphy.2018.81001

Received: October 13, 2017

Accepted: December 8, 2017

Published: December 11, 2017

Copyright (c) 2018 by authors and Scientific Research Publishing Inc. This work is licensed under the Creative Commons Attribution International License (CC BY 4.0).

http://creativecommons.org/licenses/by/4.0/

\section{c. (i) Open Access}

\begin{abstract}
We evaluate the level of knowledge of clinician doctors asking for echographies on the biological effects of ultrasounds and their attitudes towards ultrasounds examinations performed in Lome. Transverse study based on a survey led from August 16th till November 30th, 2013 including 105 doctors applicant of ultrasound in Lome (Togo). The middle age of the applicant doctors was of 34 years with a sex-ratio of $4 / 1$ and more than half practiced in public facilities. Approximately ten percent applicants thought that the ultrasound is an irradiant exam and those practicing for less than 5 years were the ones who had a good level of knowledge on the not irradiant character of the ultrasounds. The existence of the thermal and mechanical effects of the ultrasounds was known only by $4.8 \%$ of the applicants and only $1.9 \%$ of the doctors had information on the thermal index (TI) and the mechanical index (MI). More than half (66.7\%) analyzed the ultrasound images joined to the report but none verified the conformity with the standards of the values of the $\mathrm{TI}$ and at MI shown on the images. They were $43.5 \%$ to read only the conclusion. The level of knowledge of the doctors on the biological effects of the ultrasounds is unsatisfactory. The ultrasounds although not irradiant, have biological effects imposing precautionary measures which have to guide the attitude of the applicants towards the ultrasonographic explorations.
\end{abstract}




\section{Keywords}

Ultrasound, Biological Effect, Echography, Precaution Measures, Lome

\section{Introduction}

Medical ultrasonography (echography) is a medical imaging diagnostic technique based on ultrasound reflection (sounds with a frequency between $20 \mathrm{kHz}$ and $200 \mathrm{MHz}$ ). Being non-irradiant and because of its relative low cost, it is widely and frequently used in hospital environment [1]. If till this day, none deleterious effect has been formally reported in diagnostic conditions use in human being, some biological effects do exist, are real and has been described in some animals experimentally [2].

Those biological effect (thermic and mechanic) that cause pathologies such as deafness, visual acuteness, pulmonary hemorrhage and chromosomic anomalies described in some animal can occur in humans with highly acoustic power. Thus, many scientific studies exhort to a greater vigilance in diagnostic ultrasound explorations especially the use of Doppler in human medicine [3].

Unfortunately, the existence of risks with deleterious effect is a little known by doctors and rare are the studies led on the level of mastering the biological effects of ultrasound by doctors, asking for or performing ultrasound explorations. Our work aims to evaluate the level of knowledge of clinician doctors asking for echographies on the biological effects of ultrasounds and their attitudes towards ultrasounds examinations performed in Lome, Togo.

\section{Materials and Methods}

It was a transversal study made from August 16th to November 30th, 2013 including 105 Togolese doctors, general practitioners as specialists working in public and private medical facilities in Lome, the capital of Togo.

The analyzed parameters were:

- Doctor's identity: age, sex, specialty, professional experience, mode of practicing (private or public).

- Knowledge on biological effects of ultrasounds.

- Attitudes towards ultrasound explorations performed in Lome.

These parameters have allowed conceiving a survey questionnaire made essentially of multiple choice questions (MCQ).

The data were analyzed with the statistic software Sphinx $x^{\circledast}$ 5.3.1. The qualitative data were treated with Microsoft Word ${ }^{\oplus} 2013$ and the graphics with Microsoft $\mathrm{Excel}^{\circledR}$ 2013. The results were tested with Khi 2 test. All the differences inferior to 0.05 were considered significant.

\section{Results}

\subsection{General Characteristics of the Doctors}

The middle age of the doctors was 34 years with extremes from 24 to 57 years. 
Our sample was made of 83 men (79\%) and 22 women (21\%) with a sex-ratio of $4 / 1$. Most of the doctors $(60 \%)$ were specialists with a predominance of gyneco-obstetricians (Figure 1).

More than a half (73) or $69.5 \%$ worked in public medical facilities and $30.5 \%$ in private clinics. Sixty-four doctors have a professional experience of less than 5 years or $61 \%$ and 41 with more than 5 years' experience or $39 \%$. All the doctors have performed a training course in Radiology during their medical formation.

\subsection{Knowledge of Togolese Doctors on Biological Effects of Ultrasound}

About $1 / 10$ of doctors thought that echography is an irradiant exam and doctors practicing for less than 5 years were those having a good level of knowledge on the non-irradiant aspect of ultrasounds (Table 1).

The existence of thermic and mechanic effects was known only by 5 doctors or $4.8 \%$ of the cases. Only 2 gynecologists among the 105 doctors (1.9\%) have knowledge on the TI (thermic index) and MI (mechanic index).

\subsection{Attitudes of Clinician Doctors towards Ultrasound Explorations Performed in Lomé}

The majority of the doctors with less than 5 years' experience read all the report when more than $2 / 3$ practicing for more than 5 years only read the conclusion, $\mathrm{p}<0.001$ (Table 2).

Table 3 shows that all the gyneco-obstetricians and the cardiologists analyzed the images joined to the ultrasound report when all the ophthalmologists and about $2 / 3$ of pulmonologists did not. It also shows that doctors practicing for less than 5 years were those analyzing more ultrasound images joined to the report.

No doctor asking for ultrasound does verify the conformity to the standards of TI and MI values showed on the images.

In front of an ultrasound report a little or no convincing, about 3/4 of the doctors make it reperformed when a little more than a half (55.2\%) discussed with the performer (Table 4).

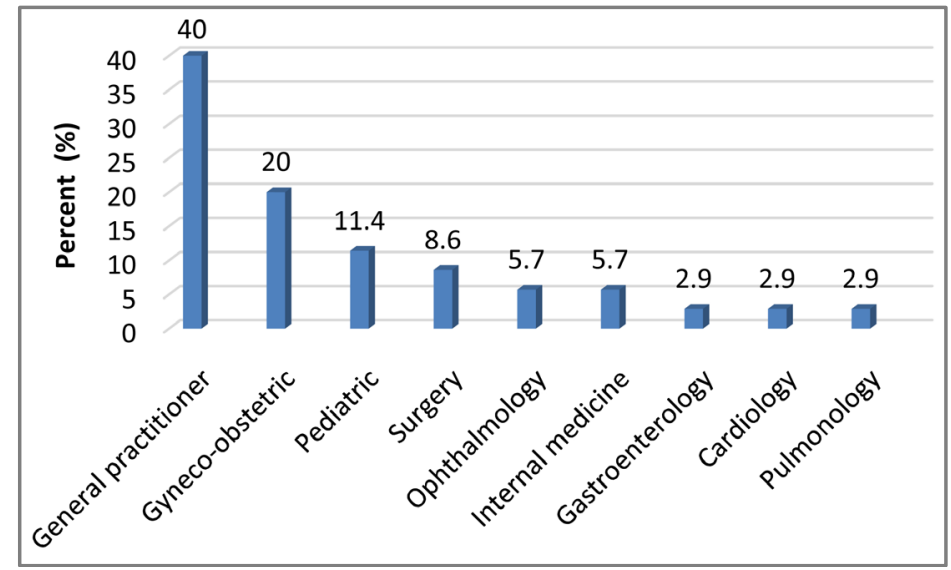

Figure 1. Repartition of doctors according to their qualification. 
Table 1. Proportion of doctors that did not know that ultrasounds are not irradiant according to their qualification and their professional experience.

\begin{tabular}{ccc}
\hline & Number & Percentage \\
\hline Qualification & 3 & \\
\hline Gastroenterology $(\mathrm{n}=3)$ & 6 & 100.0 \\
Ophthalmology $(\mathrm{n}=6)$ & 3 & 100.0 \\
Cardiology $(\mathrm{n}=3)$ & 9 & 100.0 \\
Surgery $(\mathrm{n}=9)$ & 20 & 95.2 \\
Gyneco-obstetrics $(\mathrm{n}=21)$ & 39 & 92.9 \\
General practitioner $(\mathrm{n}=42)$ & 10 & 83.3 \\
Pediatric $(\mathrm{n}=12)$ & 4 & 66.7 \\
Internal medicine $(\mathrm{n}=6)$ & 2 & 66.7 \\
Pulmonology $(\mathrm{n}=3)$ & & 93.8 \\
\hline Professional experience & 60 & 87.8 \\
\hline Less than 5 years $(\mathrm{n}=64)$ & 36 & \\
5 years and over $(\mathrm{n}=41)$ & & \\
\hline
\end{tabular}

${ }^{*} \mathrm{n}=$ Total number of doctor of the category.

Table 2. Attitude of doctors in front of ultrasound report according to their professional experience.

\begin{tabular}{clcccc}
\hline & \multicolumn{2}{c}{ Read all the report } & \multicolumn{2}{c}{ Read only the conclusion } \\
\cline { 2 - 5 } & $\mathbf{N}$ & $\%$ & N & $\%$ \\
\hline Less than 5 years $(\mathrm{n}=64)$ & 42 & 65.6 & 15 & 23.4 \\
5 years and over $(\mathrm{n}=41)$ & 21 & 51.2 & 30 & 73.2 \\
Total $(\mathrm{n}=105)$ & 63 & 60.0 & 45 & 42.9 \\
\hline
\end{tabular}

${ }^{*} \mathrm{n}=$ Total number of doctor of the category.

Table 3. Proportion of doctors analyzing the images joined to the ultrasound report according to their qualification and their professional experience.

\begin{tabular}{ccc}
\hline & Number & Percentage \\
\hline Qualification & 2 & 66.7 \\
\hline Gastroenterology $(\mathrm{n}=3)$ & 0 & 0.0 \\
Ophthalmology $(\mathrm{n}=6)$ & 3 & 100.0 \\
Cardiology $(\mathrm{n}=3)$ & 5 & 55.5 \\
Surgery $(\mathrm{n}=9)$ & 21 & 100 \\
Gyneco-obstetrics $(\mathrm{n}=21)$ & 29 & 66.7 \\
General practitioner $(\mathrm{n}=42)$ & 5 & 69.0 \\
Pediatric $(\mathrm{n}=12)$ & 4 & 41.7 \\
Internal medicine $(\mathrm{n}=6)$ & 1 & 66.7 \\
Pulmonology $(\mathrm{n}=3)$ & & 33.3 \\
\hline Professional experience & 47 & 73.4 \\
\hline Less than 5 years $(\mathrm{n}=64)$ & 23 & 56.1 \\
\hline 5 years and over $(\mathrm{n}=41)$ & &
\end{tabular}

${ }^{*} \mathrm{n}=$ Total number of doctor of the category. 
Table 4. Attitude of doctors in front of ultrasound report according to their professional experience.

\begin{tabular}{ccccc}
\hline & \multicolumn{2}{c}{ Make reperform } & \multicolumn{2}{c}{ Discuss with the performer } \\
\cline { 2 - 5 } & $\mathrm{N}$ & $\%$ & $\mathrm{~N}$ & $\%$ \\
\hline Less than 5 years $(\mathrm{n}=64)$ & 51 & 79.7 & 21 & 32.8 \\
5 years and over $(\mathrm{n}=41)$ & 25 & 61.0 & 30 & 73.2 \\
Total $(\mathrm{n}=105)$ & 63 & 60.0 & 45 & 42.9 \\
\hline
\end{tabular}

${ }^{*} \mathrm{n}=$ Total number of doctor of the category.

\section{Discussion}

Medical ultrasonography or ultrasound imaging is today the second step of patients 'care after the clinical exam particularly in emergencies [1].

Introduced in Togo in the 87's, the accessibility of echography does not cease increasing even in remoted places of the countries [4]. It would have been desirable we extended our study on the doctors of all the medical facilities even the remoted ones of Togo. Practical reasons have led us to limit our sample to doctors (105) working in Lomé. Such a choice can be a limit to this study. But, considering that the majority of Togolese doctors work in Lomé [5] and that the two reference centers of the country were concerned in this study, we estimate that our study can be extrapolate to all the Togolese doctors.

Our sample was made of 83 men and 22 women or a sex-ratio of 4 . This result is near the one found by Koffi-Tessio et al. [6]. The medical profession stills a man's work in Black Africa. This imbalance in favor of men remind what Europe faced where, during a long time, the medical profession was reserved to men [7].

The professional experience of doctors was less than 5 years in $61 \%$. This result could be explained by the availability and the keen interest of young doctors to answer the questionnaire.

It is a little bit bad that $8.6 \%$ of doctors thought that echography is an irradiant exam if we know that Adambounou et al. in 2015 [8] have found a proportion of $5.2 \%$ in radio technicians in Togo for the same question. Ultrasounds are mechanical waves that propagate only in material environment. They are different from the ionizing electromagnetic wave that are $\mathrm{X}$ and gamma rays. If ultrasounds are not ionizing and cannot lead to determinist and stochastic effects described for ionizing radiations, it is important to underline that they have too some biological effects that are specific to them. These biological effects that are unfortunately known by about $5 \%$ of the doctors included in our study, are of 2 types: thermic effects and mechanic effects. Those two effects lead to pathologic lesions that have been described in animals in experimental conditions. The thermic effect for example is the base of the therapeutic use of ultrasound [9]. However, we must insist on the fact that many epidemiologic studies [2] [10] [11] [12] [13] [14] have reported pathologies that would be related to medical ultrasonography especially gyneco-obstetrical but the scientific proof of ultrasound's guiltiness stills questionable by this time. Medical ultrasonography stills 
presumed, we say "presumed" inoffensive. Though nothing proves by this time that exposition to ultrasounds have cumulative effects in adult or fetus, it seems necessary to recommend to echographists to respect general principle ALARA (As Low As Reasonably Achievable) in their practice; it means to use the minimal output acoustic power and the minimal exposition time to obtain the necessary clinical information mostly when working on fetus.

As a matter of fact, the use of echography for pleasure or non-medical purpose should not be allowed if we consider that, at the opposite of medical echography, echography for pleasure is nothing more than a sophisticated version of photography.

For a variable cost, the surface of the fetus is covered and clients obtain souvenir photos of their fetus. During such an exam, there is no morphologic evaluation. The CAR (Canadian Association of Radiologists) talks the same way: "CAR opposes vivaciously the use of diagnostic echography material for non-medical purposes and considers that the recourse to medical echography for pleasure purpose as an abusive use of technology, in particular when talking about fetus" [15].

Our study has revealed that only $1.9 \%$ of the doctors had information on the terms: TI (thermic index) and MI (mechanic index). This result differs widely from the result of Marsal in Europe that has found a knowledge proportion of $35 \%$ for the MI and 32\% for the TI [16]. Sheiner et al. in Germany [17] have found $32 \%$ and Jennifer et al. in USA 47\% [18]. This difference could be explained by the fact that the studies made in Europe and USA were made on performers that master more these terms when our study has concerned only applicants of those exams. In fact, the TI evaluate the risk of thermic effect occurring and the MI the mechanic one. The thermic effect is shown by a temperature increase due to the transformation of acoustic energy of ultrasound in thermic energy [11]. The ultrasounds can provoke tissue heating of some Celsius degrees. The mechanic effect of ultrasounds consists in an acoustic cavitation: possibility of bubble formation by succession of positive and negative pressure.

The biological effects of ultrasounds in echography are all the more important that the ultrasound beam is focalized, that the output power of the ultrasound scanner is high and/or that the time of exposition increases [19]. As it is not possible to follow directly the temperature of exposed tissues to ultrasound, in particular fetal ones, the devices display risk indicators named thermic index (TI) and mechanic index (MI).

If it is comforting that all the gyneco-obstetricians and cardiologists of our sample analyzed the images joined to the ultrasound report, it is deplorable that none of the asker doctors of our study do verify the MI and TI to be sure that the performer of the ultrasound exploration has respected the recommended norms.

About 3/4 of the doctors make the exam reperformed when the result was not convincing them when a little bit more than a half discussed with the performer, especially those practicing for more than 5 years (senior doctors). The reason 
could be that the ones who have practiced longer could have understood the difficulty of this exam. In fact, even benefiting a continuous development of equipment more and more sophisticated, echography stills a difficult exam and operator-dependent. Reperfoming the exams delay the care of patient without bringing something concrete. Besides, these untimely repetitions of echographic explorations are contrary to precautions measures recommended for a better safety of medical ultrasonography.

The evaluation of the knowledge of the biological effects of the ultrasounds having concerned only the applicants in this study, it would thus be interesting that one study in the future include the performers (sonographers and radiologists). Such study could be spread to the radiologists and sonographers of the western Africa for example in order to have a sample of bigger size.

\section{Conclusion}

The level of knowledge of Togolese doctors on biological effects of ultrasounds is a little satisfying. Ultrasounds, even non-irradiant, have biological effects (thermic and mechanic) that impose precaution measures recommended by medical ultrasonography learned societies. These measures must lead the attitude of the applicants and also the performers towards ultrasonographic explorations. Altogether, medical ultrasonography dwells "presumed" inoffensive but vigilance is in place and passes through the surveillance of thermic and mechanic indexes showed on the ultrasound images and videos.

\section{References}

[1] Kirkpatrick, A., Sustic, A., and Blaivase, M. (2007) Introduction to the Use of Ultrasound in Critical Care Medicine. Critical Care Medicine, 35, 123-125. https://doi.org/10.1097/01.CCM.0000260622.26564.94

[2] Fowlkes, J.B., Bioeffects Committee of the American Institute of Ultrasound in Medicine (2013) American Institute of Ultrasound in Medicine Consensus Report on Potential Bioeffects of Diagnostic Ultrasound: Executive Summary.

[3] Salvesen, K.A. (2002) EFSUMB: Safety Tutorial Epidemiology of Diagnostic Ultrasound Exposure during Pregnancy /European Committee for Medical Ultrasoundsafety (ECMUS). European Journal of Ultrasound, 15, 165-171. https://doi.org/10.1016/S0929-8266(02)00038-1

[4] Adambounou, K., Farin, F., Boucher, A., Adjenou, K.V., Gbeassor, M., N'dakena, K., Vincent, N. and Arbeille, Ph. (2012) Système de télé expertise échographique temps réel et de télédiagnostic échographique temps différé. Etude pilote au Togo. Médecine et Santé Tropicales, 22, 54-60.

[5] Ministère de la santé (2012) Profil en ressources humaines pour la santé du Togo.

[6] Koffi-Tessio, A.V., Oniankitan, O. and Mijiyawa, M. (2010) Vécu et perçu de leur profession par des médecins togolais. La Tunisie Médicale, 88, 660-665.

[7] Duhamel, P. (1993) Histoire des médecins français. Plon : Paris, 392.

[8] Adambounou, K., Achy, O.B., Fiagan, Y.A., Adigo, A.M.Y., Monde, K., Gbande, P., Sonhaye, L., Tapsoba, T.L. and Adjenou, K.V. (2015) Knowledge and Attitude of Togolese Radiographers on Medical Irradiation of Pregnant Women. Journal of 
Nuclear Medicine and Radiation Therapy, S7, 003.

[9] The Safety Group of the British Medical Ultrasound Society (2010) Guidelines for the Safe Use of Diagnostic Ultrasound Equipment. Ultrasound, 18, 52-59. https://doi.org/10.1258/ult.2010.100003

[10] Campbell, J.D., Elford, R.W. and Brant, R.F. (1993) Case-Control Study of Prenatal Ultrasonography Exposure in Children with Delayed Speech. Canadian Medical Association Journal, 149, 1435-1440.

[11] Abramowicz, J.S., Barnett, S., Duck, F., Edmonds, P., Hynynen, K. and Ziskin, M. (2008) Fetal Thermal Effects of Diagnostic Ultrasound. Journal of Ultrasound in Medicine, 27, 541-559. https://doi.org/10.7863/jum.2008.27.4.541

[12] O’brien, W.D.J.R., Deng, C.X., Harris, G.R., et al. (2008) The Risk of Exposure to Diagnostic Ultrasound in Postnatal Subjects: Thermal Effects. Journal of Ultrasound in Medicine, 27, 517-535. https://doi.org/10.7863/jum.2008.27.4.517

[13] Church, C.C., Carstensen, E.L., Nyborg, W.L., Carson, P.L., Frizzell, L.A. and Bailey, M.R. (2008) The Risk of Exposure to Diagnostic Ultrasound in Postnatal Subjects: Nonthermal Mechanisms. Journal of Ultrasound in Medicine, 27, 565-592. https://doi.org/10.7863/jum.2008.27.4.565

[14] Stratmeyer, M., Greenleaf, J., Dalecki, D. and Salvesen, K. (2008) Fetal Ultrasound: Mechanical Effects. Journal of Ultrasound in Medicine, 27, 597-605. https://doi.org/10.7863/jum.2008.27.4.597

[15] Société canadienne des échographistes médicaux (2008) Lignes directrices et politiques sur la pratique professionnelle de l'échographie au Canada.

[16] Marsal, K. (2005) The Output Display Standard: Has It Missed Its Target? Ultrasound in Obstetrics \& Gynecology, 25, 211-214. https://doi.org/10.1002/uog.1864

[17] Sheiner, E., Abramowick, J. and Shoham-Vardi, I. (2007) What Do Clinical users know regarding Safety of Ultrasound during Pregnancy? Journal of Ultrasound in Medicine, 26, 319-325. https://doi.org/10.7863/jum.2007.26.3.319

[18] Jennifer, B. and Kimberly, T. (2011) Safety Pratice of Sonographers and Their Knowledge of the Biologic Effects of Sonography. Journal of Diagnostic Medical Sonography, 26, 252-261.

[19] Stratmeyer, M., Bigelow, T. and Abramowicz, J. (2011) AIUM Bioeffect Safety Committee. Bioeffects Literature Reviews. Journal of Ultrasound in Medicine, 30, 583-585. https://doi.org/10.7863/jum.2011.30.4.583 